\title{
Food Behaviors and Its Association with Hypertension and Cardiovascular Diseases in Sowme'eh Sara (North of Iran): The PERSIAN Guilan Cohort Study (PGCS)
}

\author{
Masoumeh Moslemi ${ }^{1}$, Marjan Mahdavi-Roshan ${ }^{2,3}$, Farahnaz Joukar ${ }^{4-6}$, Mohammadreza Naghipour $^{4,5}$, \\ and Fariborz Mansour-Ghanaei ${ }^{4-6}$
}

${ }^{1}$ Halal Research Center of the Islamic Republic of Iran, Ministry of Health and Medical Education, Tehran, Iran

${ }^{2}$ Cardiovascular Diseases Research Center, Department of Cardiology, Heshmat Hospital, School of Medicine,

${ }^{3}$ Department of Clinical Nutrition, School of Medicine, ${ }^{4}$ Gastrointestinal and Liver Diseases Research Center,

${ }^{5}$ Caspian Digestive Diseases Research Center, and ${ }^{6} \mathrm{Gl}$ Cancer Screening and Prevention Research Center,

Guilan University of Medical Sciences, Rasht, Iran

\begin{abstract}
Food behavior and dietary pattern are major parameters affecting the health status of people. The objective of this study was investigation of food behaviors in people inhabited in North of Iran to find out association of the effective indices (related to salt and fried foods) with hypertension and other cardiovascular diseases (CVDs). This large crosssectional study was conducted on 10,520 participants and their sociodemographic, medical, and food behavior information were evaluated. Association of salt intake with CVDs and stroke was studied by portfolio at risk (PAR) formula. Association of food behavior with hypertension and CVDs was surveyed by chi-square test. Differences were significant at $P \leq$ 0.05. Analysis of medical information revealed that $43.18 \%$ and $8.18 \%$ of the participants had hypertension and CVDs, respectively; mostly in women. Significant association was observed between salt-related behaviors and hypertension in the participants. Regarding salt intake, higher PARs were calculated in women than men (2.26 vs. 1.88 for PAR CVDs $_{\text {and } 3.66}$ vs. 3.05 for PAR $_{\text {stroke }}$ ), and urban than rural inhabitants (4.56 vs. 3.66 for PAR CvDs $_{\text {and } 7.27 \text { vs. } 5.88 \text { for PAR }}$ stroke). No significant contribution was observed between oil-related behaviors and CVDs. The majority of participants were well-informed about appropriate preparation and consumption of fried foods but not a healthy behavior about salt intake. Considering the significant association of salt-related behaviors with hypertension, conducting educational programs by healthcare practitioners in the population is suggested.
\end{abstract}

Keywords: cardiovascular diseases, food behavior, hypertension, Iran

\section{INTRODUCTION}

Non-communicable diseases (NCDs) have increased in Iran in recent decades of which cardiovascular diseases (CVDs) are the largest percentage (Moslemi et al., 2020). According to the World Health Organization (WHO), "healthy diet" is one of four behavioral factors in prevention and control of NCDs (Kopčeková et al., 2020). In this regard, dietary habits consisting of types of foods and their preparation method have great impact on health status of individuals (Mahdavi-Roshan et al., 2016; MahdaviRoshan et al., 2017). Following the global action plans aimed to decrease NCDs by governments, reformulation of industrial food products and changing the food style to deliver limited risk factors by diet have been initiated in Iran in recent years (Jamali et al., 2020; Moslemi et al., 2020). On the other hand, modernization of societies toward changes in food habits and consumption of lessnutritious foods has also increased the rate of metabolic syndromes (accounted as 38\% in Iran) which are associated with incidence of NCDs (Faramarzi et al., 2019). In the study of Faramarzi et al. (2019) rate of hunger was gradually decreased in Iran despite increased food insecurity (low intake of micronutrients). Silva et al. (2018) conducted a cohort study in Brazil and found that some social factors such as culture and economy affect the food habits, and educational programs can attenuate the adverse impact of inappropriate food habit on health sta-

Received 19 April 2021; Revised 16 May 2021; Accepted 16 May 2021; Published online 30 September 2021

Correspondence to Fariborz Mansour-Ghanaei, Tel: +98-13-33535116, E-mail: fmansourghanaei@gmail.com

Author information: Masoumeh Moslemi (Professor), Marjan Mahdavi-Roshan (Professor), Farahnaz Joukar (Professor), Mohammadreza Naghipour (Professor), Fariborz Mansour-Ghanaei (Professor) 
tus of individuals. Other researchers reported that socioeconomic status has direct impact on food habit so that people with high socioeconomic level prefer to use foods containing low salt and fat compared to others, which leads to lower risk of hypertension (Psaltopoulou et al., 2017). High consumption of red meat along with low consumption of fruits and vegetables by pregnant women in India at low socioeconomic status resulted in high gestational diabetes mellitus due to inclusion of saturated fat, cholesterol, and heme iron in red meat (Deepa et al., 2020).

Other than social factors, people may not be aware of the adverse effect of daily risk factors. For example, uncontrolled salt intake at early ages can change taste of people to high sodium meals, which can lead to high salt intake in adulthood followed by hypertension and its attributed risks (Strazzullo et al., 2009). The importance of eating behavior was also supported by Derks et al. (2018) showing high fat mass at early age induced higher food intake at higher age.

Changing food habits toward consumption of inexpensive healthy foods in appropriate ways is feasible strategy in reduction of NCDs worldwide. A balanced diet including low sodium and saturated/trans-fat and high in unsaturated fatty acids (as reported in Mediterranean diet) is recommended by the experts to prevent heart diseases (Francula-Zaninovic and Nola, 2018). To figure out the contribution of food behaviors and dietary risk factors to hypertension and other CVDs, we conducted the current study on 10,520 inhabitants of Guilan (North of Iran) for three years (2014 2017). At this work, we investigated the major food behaviors of the participants regarding the food components and the way of food preparation associated with hypertension and CVDs. This is the first study done in this regard in North of Iran and the results can be used for further strategies. Importantly, educational programs can be designed further to change the current food behavior toward a healthier lifestyle, if needed.

\section{MATERIALS AND METHODS}

\section{Participants and study design}

The present cross-sectional study was conducted within the framework of the Prospective Epidemiological Research Studies in Iran (PERSIAN) Guilan Cohort Study (PGCS). It included 10,520 participants (4,887 men and 5,633 women between 35 and 70 years old) of Sowme'eh Sara County that is in northern Iran (Fig. 1). The study was done from 8 October 2014 to 20 January 2017 as a part of the PERSIAN (Poustchi et al., 2018; MansourGhanaei et al., 2019). Our experimental protocol was approved by the Ethics Committee of Guilan University of Medical Sciences (IR.GUMS.REC.1399.370) and conformed to the ethical principles set forth in the Declaration of Helsinki. Numeric and categorical variables were classified to sociodemographic information [age, gender,
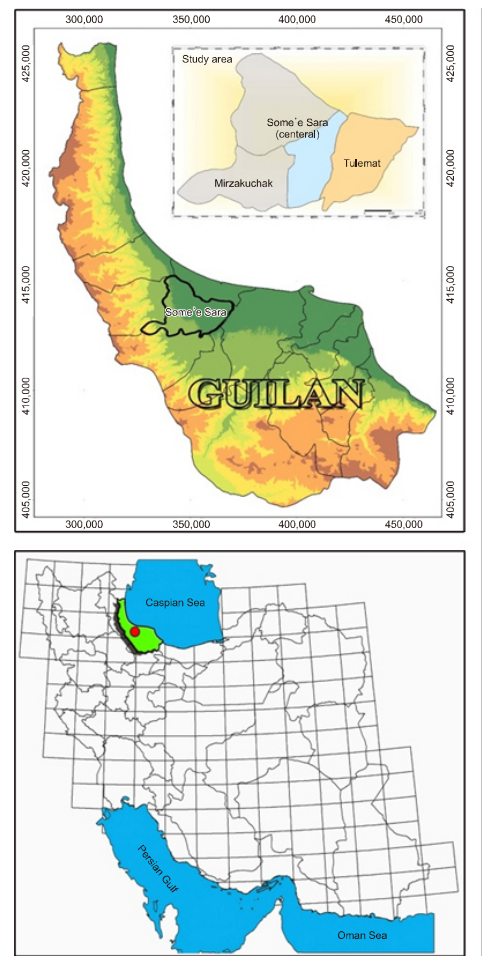

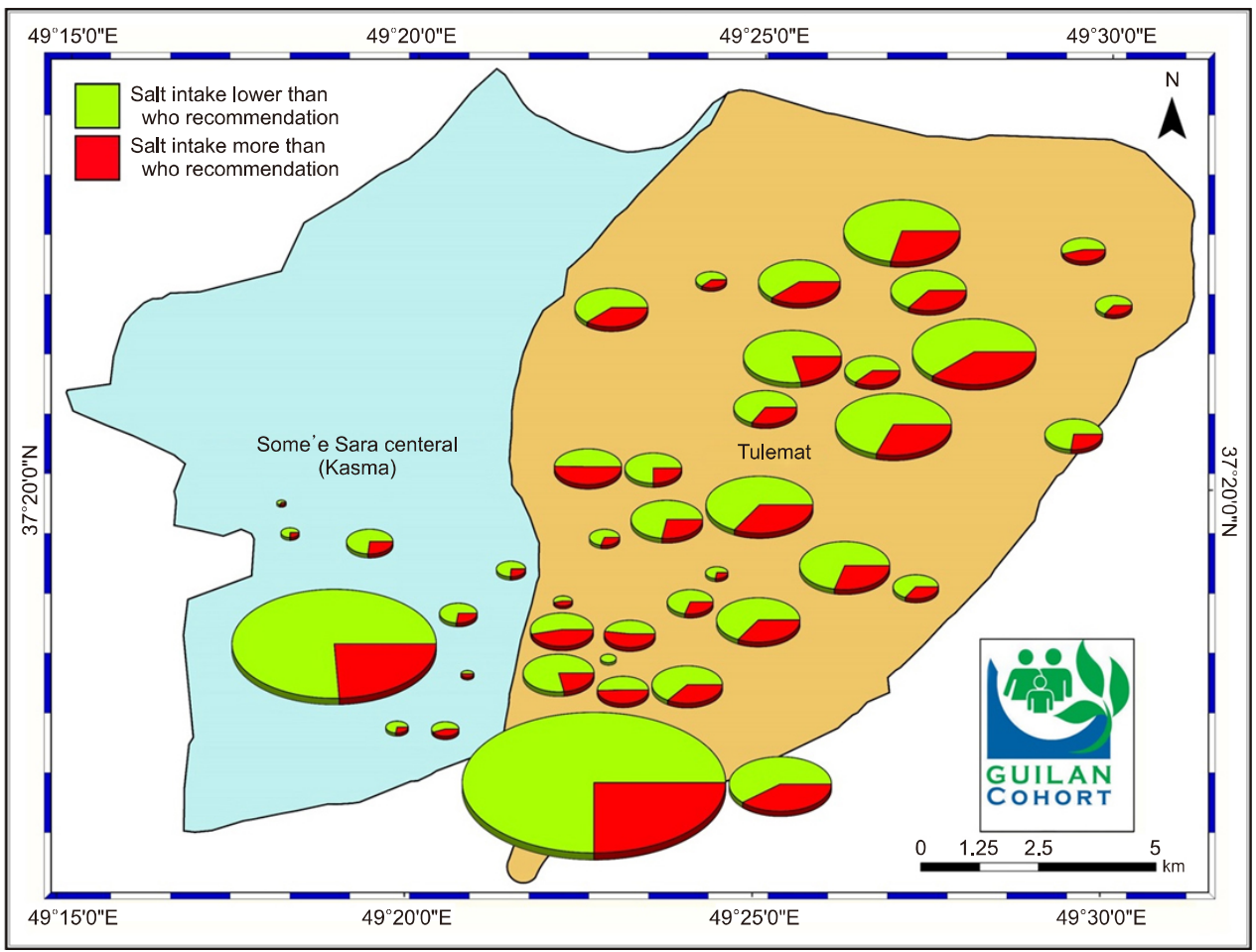

Fig. 1. Map of Sowme'eh Sara County (left) and comparative schematic of salt intake in the region regarding the WHO recommendation (right). 
body mass index (BMI), education, marital status, job, and habitat], medical information (signs of hypertension and CVDs), and food behavioral information (number of meals per day, added salt on the table, amount of salt added to food during preparation, use of fried foods, further use of remained frying oil, type of oil for frying, level of vegetables' frying, storage of vegetables in the freezer, and use of infusion). Hypertensive participants were those with diagnosed hypertension by a physician, take antihypertensive drugs, or have systolic and diastolic blood pressures equal or higher than $140 \mathrm{mmHg}$ and 90 $\mathrm{mmHg}$, respectively. CVDs included to history of cardiac ischemia and/or myocardial infarction and/or stroke (Poustchi et al., 2018; Mansour-Ghanaei et al., 2019).

\section{Statistical procedure}

Statistical analysis was done by IBM SPSS statistics 26 (SPSS Inc., Chicago, IL, USA) and significant level of 0.05 was used. Descriptive analysis was done on numeric variables and data are presented as mean \pm standard deviation (SD). Categorical variables are reported as number/percent at each sex and in total population. The food behavior data is presented in number/percent based on gender and habitat, separately. To find out the impact of daily ingested salt on incidence of CVDs and stroke, average salt intake per day (in both genders, both habitats, and total population) was calculated based on the infor- mation presented by the participants to the questioners and the following equation was used for assessment. Consideration of salt intake just included to the levels added by the participants to their foods and the amounts delivered by ready-to-eat or processed foods were not studied.

$$
\text { Population attributable risk }(\%)=\frac{\mathrm{P}_{\mathrm{e}} \times(\mathrm{RR}-1)}{\mathrm{P}_{\mathrm{e}} \times(\mathrm{RR}-1)+1}
$$

where, $\mathrm{P}_{\mathrm{e}}$ is proportion of population exposed to a risk factor (that is salt intake higher than $5 \mathrm{~g} / \mathrm{d}$ in the current work, which was determined by the WHO (2012) (Fig. 1 ), and RR is relative risk of the risk factor with regard to specific disease (1.14 for CVDs and 1.23 for stroke, in the current work) (Strazzullo et al., 2009; Moslemi et al., 2020).

To understand the association of the food behavioral parameters and hypertension/CVDs, chi-square test was done and parameters of Pearson chi-square value, Phi and Cramer's V, and $P$-value were investigated.

\section{RESULTS}

Sociodemographic information is reported in Table 1. According to the Table 1, evaluation of medical information

Table 1. Sociodemographic and medical information of the participants in the PERSIAN Guilan cohort study (PGCS)

\begin{tabular}{|c|c|c|c|c|}
\hline Parameter & Men $(n=4,887)$ & Women $(n=5,633)$ & Total $(n=10,520)$ & $P$-value \\
\hline Age (year) & $48.47 \pm 8.86$ & $48.55 \pm 8.94$ & $48.52 \pm 8.90$ & 0.215 \\
\hline BMI $\left(\mathrm{kg} / \mathrm{m}^{2}\right)$ & $26.08 \pm 4.20$ & $29.93 \pm 5.11$ & $28.14 \pm 5.09$ & $<0.001$ \\
\hline Education (years) & & & & $<0.001$ \\
\hline 0 (illiterate) & $506(10.35)$ & $1,232(21.87)$ & $1,738(16.52)$ & \\
\hline$\leq 12$ & $3,925(80.32)$ & $4,219(74.90)$ & $8,144(77.41)$ & \\
\hline $13 \sim 16$ & 414 (8.47) & $172(3.05)$ & $586(5.57)$ & \\
\hline$\geq 17$ & $42(0.86)$ & $10(0.18)$ & $52(0.49)$ & \\
\hline Marital status & & & & $<0.001$ \\
\hline Single & $78(1.60)$ & $227(4.00)$ & 305 (2.90) & \\
\hline Married & 4,733 (96.80) & $4,794(85.10)$ & $9,527(90.56)$ & \\
\hline Widow & $48(1.00)$ & $518(9.20)$ & $566(5.38)$ & \\
\hline Divorced & $28(0.60)$ & $94(1.70)$ & $122(1.16)$ & \\
\hline Job & & & & $<0.001$ \\
\hline Yes & $4,325(88.50)$ & $1,414(25.10)$ & $5,739(54.55)$ & \\
\hline No & $562(11.50)$ & $4,219(74.90)$ & $4,781(45.45)$ & \\
\hline Habitat & & & & $<0.001$ \\
\hline Rural & $2,825(57.80)$ & 3,082 (54.70) & $5,907(56.15)$ & \\
\hline Urban & $2,062(42.20)$ & $2,551(45.30)$ & $4,613(43.85)$ & \\
\hline Hypertension & & & & $<0.001$ \\
\hline Yes & $1,904(39.00)$ & $2,639(46.80)$ & 4,543 (43.18) & \\
\hline No & $2,983(61.00)$ & $2,994(53.20)$ & $5,977(56.82)$ & \\
\hline CVDs $^{1)}$ & & & & 0.652 \\
\hline Yes & $376(7.69)$ & $484(8.59)$ & $860(8.18)$ & \\
\hline No & $4,511(92.31)$ & $5,149(91.41)$ & $9,660(91.82)$ & \\
\hline
\end{tabular}

Data are presented as mean $\pm \mathrm{SD}$ or $\mathrm{n}(\%)$.

${ }^{11} \mathrm{CVD}$, cardiovascular diseases; it included to cardiac ischemia and/or myocardial infarction and/or stroke. 
revealed that rate of hypertension and CVDs in women ( $46.80 \%$ and $8.59 \%$, respectively) was higher than men (39.00\% and $7.69 \%$, respectively).

Food behaviors of the participants are presented in Table 2 . We observed that more than $60 \%$ of the participants in both gender and habitat groups had four meals per day. The majority of the population added no salt to foods on the table and more than $60 \%$ of the participants added moderate amount of salt to their foods during preparation. Most of the population ate fried foods 1 3 meals per week and more than $90 \%$ did not use the remained frying oil further. In term of oil type for frying, $76.79 \%$ of total population used frying oil. Totally, 50.33 $\%$ of the people fried vegetables moderately and about $88 \sim 89 \%$ of the total population froze the vegetables in fried form. Of the total participants, $27.35 \%$ used herbal infusions.

As seen in Table 3, the average salt intake was lower than the maximum recommended level of $5 \mathrm{~g} / \mathrm{d}$, but salt intake in women was higher than men and in urban peo-

Table 2. Food behavioral information of the participants in the PERSIAN Guilan cohort study (PGCS)

\begin{tabular}{|c|c|c|c|c|c|c|c|}
\hline Parameter & $\begin{array}{c}\text { Men } \\
(n=4,887)\end{array}$ & $\begin{array}{l}\text { Women } \\
(n=5,633)\end{array}$ & $\begin{array}{c}\text { Total } \\
(n=10,520)\end{array}$ & $P$-value & $\begin{array}{c}\text { Rural } \\
(n=5,907)\end{array}$ & $\begin{array}{c}\text { Urban } \\
(n=4,613)\end{array}$ & $P$-value \\
\hline \multicolumn{4}{|l|}{ Number of meals/d } & 0.465 & & & 0.771 \\
\hline$<3$ meals & $65(1.33)$ & $60(1.06)$ & $125(1.19)$ & & $67(1.13)$ & $58(1.26)$ & \\
\hline 3 meals & $1,497(30.63)$ & $1,770(31.42)$ & $3,267(31.06)$ & & $1,832(31.01)$ & $1,435(31.11)$ & \\
\hline 4 meals & 3,142 (64.29) & $3,554(63.09)$ & $6,696(63.65)$ & & $3,764(63.72)$ & $2,932(63.56)$ & \\
\hline $5 \sim 6$ meals & $181(3.70)$ & $246(4.37)$ & $427(4.06)$ & & $242(4.10)$ & $185(4.01)$ & \\
\hline $6<$ meals & $2(0.04)$ & $3(0.05)$ & $5(0.05)$ & & $2(0.03)$ & $3(0.06)$ & \\
\hline \multicolumn{4}{|l|}{ Added salt on the table } & 0.01 & & & 0.999 \\
\hline Yes & $1,051(21.51)$ & $1,138(20.20)$ & $2,189(20.81)$ & & $1,228(20.79)$ & $961(20.83)$ & \\
\hline Sometimes & 833 (17.04) & 922 (16.37) & $1,755(16.68)$ & & $988(16.73)$ & $767(16.63)$ & \\
\hline No & $3,003(61.45)$ & $3,573(63.43)$ & $6,576(62.51)$ & & $3,691(62.48)$ & $2,885(62.54)$ & \\
\hline \multicolumn{4}{|c|}{ Amount of salt added to food during preparation } & 0.228 & & & 0.013 \\
\hline Little & $1,354(27.71)$ & $1,512(26.84)$ & $2,866(27.24)$ & & $1,622(27.46)$ & $1,244(26.97)$ & \\
\hline Moderate & $3,034(62.08)$ & $3,561(63.22)$ & $6,595(62.69)$ & & $3,718(62.94)$ & $2,877(62.37)$ & \\
\hline High & $4,99(10.21)$ & $560(9.94)$ & $1,059(10.07)$ & & $567(9.60)$ & $492(10.67)$ & \\
\hline \multicolumn{4}{|l|}{ Use of fried foods } & 0.684 & & & 0.088 \\
\hline At all & $28(0.57)$ & $30(0.53)$ & $58(0.55)$ & & $35(0.59)$ & $23(0.50)$ & \\
\hline$<1$ meal a month & $12(0.25)$ & $21(0.37)$ & $33(0.31)$ & & $20(0.34)$ & $13(0.28)$ & \\
\hline $1 \sim 3$ meals a month & $216(4.42)$ & $243(4.31)$ & $459(4.36)$ & & $286(4.84)$ & $173(3.75)$ & \\
\hline $1 \sim 3$ meals a week & $3,093(63.29)$ & $3,580(63.55)$ & $6,673(63.43)$ & & 3,780 (63.99) & $2,893(62.71)$ & \\
\hline Every day & $1,538(31.47)$ & $1,759(31.23)$ & $3,297(31.34)$ & & $1,786(30.24)$ & $1,511(32.76)$ & \\
\hline \multicolumn{4}{|c|}{ Further use of remained frying oil } & 0.006 & & & $<0.001$ \\
\hline Yes & $365(7.47)$ & $461(8.18)$ & $826(7.85)$ & & $494(8.36)$ & $332(7.20)$ & \\
\hline No & 4,522 (92.53) & $5,172(91.82)$ & $9,694(92.15)$ & & $5,413(91.64)$ & $4,281(92.80)$ & \\
\hline \multicolumn{4}{|l|}{ Type of oil for frying } & $<0.001$ & & & $<0.001$ \\
\hline Solid oil & $388(7.94)$ & $519(9.21)$ & $907(8.62)$ & & $449(7.60)$ & $458(9.93)$ & \\
\hline $\mathrm{PHO}$ & $554(11.34)$ & $657(11.66)$ & $1,211(11.51)$ & & $528(8.94)$ & $683(14.81)$ & \\
\hline Cooking oil & $97(1.98)$ & $116(2.06)$ & $213(2.02)$ & & $154(2.61)$ & $59(1.28)$ & \\
\hline Frying oil & $3,793(77.61)$ & $4,285(76.07)$ & $8,078(76.79)$ & & $4,695(79.48)$ & $3,383(73.34)$ & \\
\hline Others & $55(1.12)$ & $56(0.99)$ & $111(1.06)$ & & $81(1.37)$ & $30(0.65)$ & \\
\hline \multicolumn{4}{|l|}{ Level of vegetables' frying } & 0.234 & & & 0.31 \\
\hline Stir-frying & $108(2.21)$ & $138(2.45)$ & $246(2.34)$ & & $135(2.28)$ & $111(2.41)$ & \\
\hline Moderately frying & $2,498(51.12)$ & $2,797(49.65)$ & $5,295(50.33)$ & & $2,989(50.60)$ & 2,306 (49.99) & \\
\hline Severely frying & $2,261(46.27)$ & $2,672(47.44)$ & $4,933(46.89)$ & & $2,762(46.76)$ & $2,171(47.06)$ & \\
\hline No frying & $20(0.41)$ & $26(0.46)$ & $46(0.44)$ & & $21(0.36)$ & $25(0.54)$ & \\
\hline \multicolumn{4}{|c|}{ Storage way of vegetables in freezer } & 0.304 & & & 0.005 \\
\hline Raw & $517(10.58)$ & $616(10.94)$ & $1,133(10.77)$ & & $666(11.28)$ & $467(10.12)$ & \\
\hline Cooked & $23(0.47)$ & $23(0.41)$ & $46(0.44)$ & & $31(0.52)$ & $15(0.32)$ & \\
\hline Fried & 4,338 (88.77) & 4,982 (88.44) & 9,320 (88.59) & & 5,201 (88.05) & 4,119 (89.29) & \\
\hline $\begin{array}{l}\text { No storage (using } \\
\text { fresh vegetables) }\end{array}$ & $9(0.18)$ & $12(0.21)$ & $21(0.20)$ & & $9(0.15)$ & $12(0.26)$ & \\
\hline \multicolumn{4}{|l|}{ Use of infusion } & 0.001 & & & $<0.001$ \\
\hline Yes & $1,299(26.58)$ & $1,578(28.01)$ & 2,877 (27.35) & & $1,888(31.96)$ & 989 (21.44) & \\
\hline No & $3,588(73.42)$ & $4,055(71.99)$ & $7,643(72.65)$ & & 4,019 (68.04) & $3,624(78.56)$ & \\
\hline
\end{tabular}

Data are presented as $\mathrm{n}(\%)$.

$\mathrm{PHO}$, partially hydrogenated oil. 
Table 3. Average salt intake in the population and its correlation with prevalence of cardiovascular diseases and stroke in the participants of the PERSIAN Guilan cohort study (PGCS)

\begin{tabular}{lcccc}
\hline Participants & $\begin{array}{c}\text { Salt intake } \\
\text { (g/d) }\end{array}$ & $\begin{array}{c}\text { Participants at } \\
\text { risk }^{2} \text { [n (\%)] }\end{array}$ & $\begin{array}{c}\mathrm{PAR}_{\text {CVDs }} \\
(\%)\end{array}$ & $\begin{array}{c}\text { PAR } \\
(\%)\end{array}$ \\
\hline Men & $4.20 \pm 2.70$ & $1,438(13.67)$ & 1.88 & 3.05 \\
Women & $4.26 \pm 2.66$ & $1,738(16.52)$ & 2.26 & 3.66 \\
Rural & $4.06 \pm 2.60$ & $1,603(27.14)$ & 3.66 & 5.88 \\
Urban & $4.46 \pm 2.76$ & $1,573(34.10)$ & 4.56 & 7.27 \\
Total & $4.23 \pm 2.68$ & $3,176(30.19)$ & 4.05 & 6.49
\end{tabular}

PAR, population attributable risk; CVDs, cardiovascular diseases; it included cardiac ischemia and/or myocardial infarction and/or stroke.

${ }^{1)}$ Salt intake just included to the amounts added by the participants to their foods not the amounts delivered by ready-toeat or processed foods. This amount was calculated based on the information presented by the participants to the questioners. Data are presented as mean \pm SD.

${ }^{2)}$ Those with salt intake more than $5 \mathrm{~g} / \mathrm{d}$.

ple was higher than rural inhabitants. In the total population, $4.05 \%$ of CVDs and $6.49 \%$ of stroke was related to high salt intake. Regarding CVDs, $1.88 \%$ of male and $2.26 \%$ of female patients were probably affected due to high salt intake. It was estimated as $3.66 \%$ and $4.56 \%$ in rural and urban habitants, respectively. For stroke, 3.05\% of male, $3.66 \%$ of female, $5.88 \%$ of rural, and $7.27 \%$ of urban patients were affected by high salt intake.

As expected, there was statistically significant association between salt intake and hypertension in the population about both "added salt to foods on the table" and "amount of salt added to food during preparation" parameters. Salt intake behaviors had no significant impact on CVDs. Meanwhile, no significant correlation was observed between oil intake behavior ("use of fried foods" and "reuse of remained frying oil") and CVDs in the population $(P>0.05)$. However, use of fried foods significantly correlated with hypertension (Table 4 ).

\section{DISCUSSION}

Food literacy is a scientific concept about control and prevention of food-borne diseases. Today, several communities are trying to change the human lifestyle by improvement of their food and nutrition literacy to avoid the diseases arising from foods (Razavi et al., 2020; US Preventive Services Task Force et al., 2020). Owing to the high morbidity and mortality induced by NCDs in the world, increasing attention is paid to these illnesses and several interventions are programmed in this regard. As reported, CVDs are introduced as the top one among all causalities of NCDs (Peters et al., 2019). Importantly, hypertension plays the main role in etiology of CVDs, which can be controlled by diet intervention and improvement of dietary knowledge in the population as adjuvant treatment to medication. In addition, inappropriate eating behavior is recognized as a significant risk factor in prevalence of overweight and obesity that are other causalities of CVDs (Khan et al., 2018). Eating behavior is affected by biological and social parameters. They include emotional over/under eating, continued/stopped eating after activation of satiety signal, fast/slow eating, and tendency to eat unhealthy foods containing high sodium and fat due to their palatability (Sánchez et al., 2016). The current work is the first study conducted on the inhabitants of north of Iran to figure out their food behavior and its relevance to hypertension and CVDs. Also, sociodemographic parameters were also investigated to find out their possible impact on the diseases.

Factors associated with hypertension in the current study As mentioned earlier, significant association was observed between salt-related behaviors and hypertension in the participants. The higher hypertension in women from our study might be due to their higher average salt intake per day than men. Furthermore, a higher proportion of women took salt more than the maximum recommendation $(5 \mathrm{~g} / \mathrm{d})$. It might be due to the higher percent of illiterate

Table 4. Association of food behaviors with hypertension and cardiovascular diseases in the participants of the PERSIAN Guilan cohort study (PGCS)

\begin{tabular}{|c|c|c|c|c|c|}
\hline Food behavior & Disease & $\begin{array}{l}\text { Pearson } \\
\text { chi-square } \\
\text { value }\end{array}$ & $P$-value & $\begin{array}{l}\text { Phi value/ } \\
\text { Cramer's } \\
\text { V value }\end{array}$ & $P$-value \\
\hline Added salt on the table & Hypertension & 9.191 & 0.01 & $0.03 / 0.03$ & 0.01 \\
\hline Amount of salt added to food during preparation & Hypertension & 103.731 & $<0.001$ & $0.099 / 0.099$ & $<0.001$ \\
\hline Added salt on the table & CVDs & 0.207 & 0.902 & $0.004 / 0.004$ & 0.902 \\
\hline Amount of salt added to food during preparation & CVDs & 3.481 & 0.481 & $0.018 / 0.018$ & 0.481 \\
\hline Use of fried foods & Hypertension & 23.530 & $<0.001$ & $0.047 / 0.047$ & $<0.001$ \\
\hline Further use of remained frying oil & Hypertension & 0.118 & 0.731 & $-0.003 / 0.003$ & 0.731 \\
\hline Use of fried foods & CVDs & 2.613 & 0.759 & $0.016 / 0.016$ & 0.759 \\
\hline Further use of remained frying oil & CVDs & 0.745 & 0.388 & $0.008 / 0.008$ & 0.388 \\
\hline
\end{tabular}

CVDs: cardiovascular diseases; it included cardiac ischemia and/or myocardial infarction and/or stroke. 
women not aware of salt's disadvantage and more literate men (especially at college level), which were accustomed to the adverse impact of salt on hypertension. In agreement, Geaney et al. (2015) observed indirect association between dietary knowledge of Irish population and hypertension. In the study of Chongthawonsatid (2015), Thai women showed 1.4 times more hypertension rate than Thai men. The author believed that it was due to higher physical activity of men compared to women. In our study, a higher percent of men used high table salt and high salt during food preparation. In accordance with Chongthawonsatid (2015), the lower hypertension at this group might be due to their adherence to more exercise compared to women, which attenuates the adverse impact of higher salt intake to some extent. It is confirmed by the lower contribution of salt intake to CVDs and stroke in men (Table 3). Moreover, $57.8 \%$ of male participants lived in rural regions commonly with no or low sedentary lifestyle. Interestingly, lower contribution of salt intake to CVDs and stroke was also observed in rural group than those living in urban area. This might be due to higher consumption of homemade foods at rural than urban regions. Accordingly, Trapl et al. (2018) tried to change the food habit of patients suffering from hypertension towards decreasing consumption of fast foods containing high salt and more fruits and vegetables, instead. The significant correlation of fried food consumption with hypertension (Table 4) might be another reason for the higher rate of hypertension in urban populations. As seen in Table 2, a greater percent of urban populations consumed fried foods every day compared to rural people. Additionally, social parameters affect hypertension as reported by Irving et al. (2014) so that there was association between food insecurity and hypertension. Our investigation demonstrated that a high number of women had no job and more women lived alone compared to men, which might be effective in their higher stress with regard to food insecurity.

\section{Factors associated with CVDs in the current study}

In term of CVDs, more prevalence was also observed in women. The BMI revealed that female participants were less concerned about their weight gain, which is directly associated with CVDs (Khan et al., 2018). However, no significant correlation was observed for fried foods and further use of remained frying oil with CVDs in the population. This result was expected regarding reuse of frying oil, since more than $90 \%$ of the participants did not reuse frying oil in both gender and habitat groups. Although the majority of the participants ate fried foods up to three meals a week, most of them used frying oil for this purpose, which is more resistant than the others against high temperatures (Madhujith and Sivakanthan, 2018). This healthful behavior was possibly driven fol- lowing the catastrophe in 2014 when large quantities of palm oil were imported to the country and used in production of oil products such as frying oil. Since then, oil industries have tried to reformulate the frying oils and introduced palm-free products thorough which people has been informed by the government and social advertisements (Moslemi et al., 2020). Mandatory insertion of a nutritional traffic light which shows the amount of trans fatty acids in the products is another conductive approach in training people to prepare a healthier food basket (Moslemi et al., 2020). More importantly, there was a tendency to use herbal infusions especially in rural participants. Herbal infusions are full of antioxidants, active against free radicals and can remediate the harsh impact of oxidative stress induced by free radical activity in the body, if consumed at adequate levels (Talib et al., 2020). The majority of participants (88.59\%) froze vegetables after frying which inactivates degrading enzymes in the raw vegetables without the loss of bioactive compounds (Zhan et al., 2019; Mehmood and Zeb, 2020). The level of frying confirmed it so that $52.67 \%$ of the participants stir- to moderately-fried the vegetables by which their bioactive components were well-retained.

The large sample size and geographical distribution of the participants from both rural and urban areas increased the accuracy and reliability of the results. However, our work was a cross-sectional study through which etiology evaluations were limited. Moreover, salt intake calculation was based on the amount of salt added by the participants to their foods and salt intake from ready-toeat or processed foods was not calculated.

The current work was done in a large population of North of Iran for the first time to investigate their food behaviors. We further found a significant contribution of their food behaviors to hypertension that was possibly due to high daily salt intake, high BMI, and frequent use of fried foods by a portion of the population to some extent. In addition, no significant association was observed in term of fried foods and CVDs in the participants. It was likely due to a healthy food behavior by use of frying oil in food preparation and no reusing the frying oil by most of the participants.

\section{FUNDING}

The current work was funded by Vice Chancellor for research of Guilan University of Medical Sciences (GUMS) and the Ministry of Health of Iran.

\section{AUTHOR DISCLOSURE STATEMENT}

The authors declare no conflict of interest. 


\section{REFERENCES}

Chongthawonsatid S. Demographic factors and health care behavior of hypertension disease in Thailand. Silpakorn U Sci Tech J. 2015. 9:9-16.

Deepa R, Lewis MG, Van Schayck OCP, Babu GR. Food habits in pregnancy and its association with gestational diabetes mellitus: results from a prospective cohort study in public hospitals of urban India. BMC Nutr. 2020. 6:63. https://doi.org/10. 1186/s40795-020-00388-x

Derks IPM, Sijbrands EJG, Wake M, Qureshi F, van der Ende J, Hillegers MHJ, et al. Eating behavior and body composition across childhood: a prospective cohort study. Int J Behav Nutr Phys Act. 2018. 15:96. https://doi.org/10.1186/s12966-0180725-x

Faramarzi E, Somi M, Ostadrahimi A, Dastgiri S, Ghayour Nahand M, Asgari Jafarabadi M, et al. Association between food insecurity and metabolic syndrome in North West of Iran: Azar Cohort study. J Cardiovasc Thorac Res. 2019. 11:196-202.

Francula-Zaninovic S, Nola IA. Management of measurable variable cardiovascular disease' risk factors. Curr Cardiol Rev. 2018. 14:153-163.

Geaney F, Fitzgerald S, Harrington JM, Kelly C, Greiner BA, Perry IJ. Nutrition knowledge, diet quality and hypertension in a working population. Prev Med Rep. 2015. 2:105-113.

Irving SM, Njai RS, Siegel PZ. Food insecurity and self-reported hypertension among Hispanic, black, and white adults in 12 states, Behavioral Risk Factor Surveillance System, 2009. Prev Chronic Dis. 2014. 11:E161. https://doi.org/10.5888/pcd11. 140190

Jamali A, Moslemi M, Akramzadeh N, Khaneghah AM, Dadgarnejad M. Safety factors of oils marketed in Iran and applicable strategies in control of food derived cardiovascular diseases. Curr Nutr Food Sci. 2020. 16:571-577.

Khan SS, Ning H, Wilkins JT, Allen N, Carnethon M, Berry JD, et al. Association of body mass index with lifetime risk of cardiovascular disease and compression of morbidity. JAMA Cardiol. 2018. 3:280-287.

Kopčeková J, Holovičová M, Gažarová M, Mrázová J, Habánová M, Mečiarová L, et al. Association between selected dietary habits and lipid profiles of patients with cardiovascular disease. Int J Environ Res Public Health. 2020. 17:7605. https:// doi.org/10.3390/ijerph17207605

Madhujith T, Sivakanthan S. Oxidative stability of edible plant oils. In: Mérillon JM, Ramawat KG. Bioactive Molecules in Food. Springer, Cham, Switzerland. 2018. 529-551.

Mahdavi-Roshan M, Nasrollahzadeh J, Mohammad Zadeh A, Zahedmehr A. Does garlic supplementation control blood pressure in patients with severe coronary artery disease? A clinical trial study. Iran Red Crescent Med J. 2016. 18:e23871. https:// doi.org/10.5812/ircmj.23871

Mahdavi-Roshan M, Salari A, Ggholipour M, Naghshbandi M. Dietary adherence in people with cardiovascular risk factors living in Northern Iran. J Babol Univ Med Sci. 2017. 19:62-68.

Mansour-Ghanaei F, Joukar F, Naghipour MR, Sepanlou SG, Poustchi H, Mojtahedi K, et al. The PERSIAN Guilan Cohort Study (PGCS). Arch Iran Med. 2019. 22:39-45.

Mehmood A, Zeb A. Effects of different cooking techniques on bioactive contents of leafy vegetables. Int J Gastron Food Sci. 2020. 22:100246. https://doi.org/10.1016/j.ijgfs.2020.100246

Moslemi M, Kheirandish M, Mazaheri RNF, Hosseini H, Jannat B, Mofid V, et al. National food policies in the Islamic Republic of Iran aimed at control and prevention of noncommunicable diseases. East Mediterr Health J. 2020. 26:1556-1564.

Peters R, Ee N, Peters J, Beckett N, Booth A, Rockwood K, et al. Common risk factors for major noncommunicable disease, a systematic overview of reviews and commentary: the implied potential for targeted risk reduction. Ther Adv Chronic Dis. 2019. 10:2040622319880392. https://doi.org/10.1177/ 2040622319880392

Poustchi H, Eghtesad S, Kamangar F, Etemadi A, Keshtkar AA, Hekmatdoost A, et al. Prospective epidemiological research studies in Iran (the PERSIAN Cohort Study): rationale, objectives, and design. Am J Epidemiol. 2018. 187:647-655.

Psaltopoulou T, Hatzis G, Papageorgiou N, Androulakis E, Briasoulis A, Tousoulis D. Socioeconomic status and risk factors for cardiovascular disease: impact of dietary mediators. Hellenic J Cardiol. 2017. 58:32-42.

Razavi AC, Dyer A, Jones M, Sapin A, Caraballo G, Nace H, et al. Achieving dietary sodium recommendations and atherosclerotic cardiovascular disease prevention through culinary medicine education. Nutrients. 2020. 12:3632. https://doi.org/ 10.3390/nu12123632

Sánchez U, Weisstaub G, Santos JL, Corvalán C, Uauy R. GOCS cohort: children's eating behavior scores and BMI. Eur J Clin Nutr. 2016. 70:925-928.

Silva FM, Giatti L, de Figueiredo RC, Molina MDCB, de Oliveira Cardoso L, Duncan BB, et al. Consumption of ultra-processed food and obesity: cross sectional results from the Brazilian Longitudinal Study of Adult Health (ELSA-Brasil) cohort (2008-2010). Public Health Nutr. 2018. 21:2271-2279.

Strazzullo P, Kandala NB, Cappuccio FP. Salt intake, stroke, and cardiovascular disease: meta-analysis of prospective studies. BMJ. 2009. 339:b4567. https://doi.org/10.1136/bmj.b4567

Talib WH, Al-Ataby IA, Mahmod AI, Jawarneh S, Al Kury LT, Al-Yasari IH. The impact of herbal infusion consumption on oxidative stress and cancer: the good, the bad, the misunderstood. Molecules. 2020. 25:4207. https://doi.org/10.3390/ molecules 25184207

Trapl ES, Smith S, Joshi K, Osborne A, Benko M, Matos AT, et al. Dietary impact of produce prescriptions for patients with hypertension. Prev Chronic Dis. 2018. 15:E138. https://doi.org/ 10.5888/pcd15.180301

US Preventive Services Task Force; Krist AH, Davidson KW, Mangione CM, Barry MJ, Cabana M, Caughey AB, et al. Behavioral counseling interventions to promote a healthy diet and physical activity for cardiovascular disease prevention in adults with cardiovascular risk factors: us preventive services task force recommendation statement. JAMA. 2020. 324:20692075.

WHO. Guideline: sodium intake for adults and children. 2012 [cited 2012 Dec 25]. Available from: https://www.who.int/ publications/i/item/9789241504836

Zhan X, Zhu Z, Sun DW. Effects of pretreatments on quality attributes of long-term deep frozen storage of vegetables: a review. Crit Rev Food Sci Nutr. 2019. 59:743-757. 